\title{
Prevalência de neoplasias mamárias em cadelas associadas ao uso de contraceptivos hormonais no centro de controle de zoonoses em Resende/RJ no ano de 2019
}

\section{Yasmin Bianca Guimarães de Carvalho}

Centro Universitário de Barra Mansa - UBM- Barra Mansa - RJ - Brasil

Médica Veterinária autônoma CRMV/RJ 15825

ORCID: http://orcid.org/0000-0002-8897-3549

E-mail: yasmiinvet@gmail.com

\section{Jaci de Almeida}

Centro Universitário de Barra Mansa - UBM. Barra Mansa - RJ - Brasil Médico Veterinário CRMV/RJ 9263 e Professor titular de Reprodução Animal do Curso de Medicina Veterinária do Centro Universitário de Barra Mansa - UBM.

ORCID: https://orcid.org/0000-0002-8110-9504

E-mail: jaciveterinariorj@gmail.com






\section{Resumo}

As neoplasias de glândulas mamárias são frequentes em cadelas, tendo como indutores diversos fatores como genética, idade, raça e hormônios. A incidência aumenta ainda mais com o uso de contraceptivos hormonais para prevenção do estro, principalmente por este método (farmacológico) ser de baixo custo comparado ao método cirúrgico. Um dos motivos que tem colaborado para a persistência do problema, por várias décadas, é a falta de orientação adequada aos proprietários dos animais, visando à saúde, bem estar e vida mais longeva dos animais. Nesse contexto, o presente trabalho teve por objetivo realizar um levantamento da prevalência de patologias reprodutivas em cadelas submetidas à esterilização cirúrgica e sua correlação com o uso de contraceptivos hormonais nos animais atendidos no Centro de Controle de Zoonoses de Resende - RJ.

Palavras-chave: oncologia; tumor de mama; ovariosalpingohisterectomia.

\section{Abstract}

Neoplasms of mammary glands are frequent in female dogs, having inducers several factors such as genetics, age, race and hormones. The incidence increases even more with the use of hormonal contraceptives to prevent estrus, mainly because this method (pharmacological) is of low cost compared to the surgical method. One of the reasons that has contributed to the persistence of the problem, for several decades, is the lack of adequate guidance to the owners of the animals, aiming at the health, well-being and longer life of the animals. In this context, the present study aimed to survey the prevalence of reproductive pathologies in dogs submitted to surgical sterilization and its correlation with the use of hormonal contraceptives in the animals treated at the Zoonosis Control Center in Resende - RJ.

Keywords: oncology; breast tumor; ovariosalpingohisterectomy.

\section{Introdução}

A Associação Brasileira das Indústrias de Produtos para Animais de Estimação (ABINPET) relatou que, nos domicílios do Brasil, existem 52,2 milhões de cães (IBGE, 2016). Dessa forma, o Brasil se destaca como o 4⿳⺈⿴囗十一 maior País do mundo em população total de animais de estimação. Para Queiroga e Lopes 
(2002) e Carvalho et al. (2008) o aumento da população de cães e de sua expectativa de vida é proporcional ao crescimento da população humana nos grandes centros urbanos, o que repercute na crescente casuística de atendimento veterinário clínico e cirúrgico, principalmente das intervenções cirúrgicas oncológicas.

As neoplasias de glândulas mamárias são mais frequentes em cadelas, representando cerca de 70\% de todas as neoplasias (MERLO, 2008 e HENRY, 2010). Geralmente acometem fêmeas de meia idade a idosas, com faixa etária entre 10 e 12 anos, e que não são castradas ou foram castradas em uma idade mais avançada (DE NARDI et al., 2016). Cerca da metade dos tumores mamários são malignos, considerando um prognóstico de reservado a ruim, com períodos de sobrevida significativamente menores.

No $34^{\circ}$ Congresso Brasileiro da Anclivepa, Bittencourt (2013) reportou que o controle populacional de cães e gatos e consequentemente das zoonoses devem ser contemplados em programas ou políticas públicas para essas espécies como também das ações em guarda responsável, várias ações como mutirões e programas municipais para esterilização cirúrgica, como também das unidades móveis de esterilização estão acontecendo em vários municípios brasileiros já que, frente às diversas enfermidades que podem acometê-los, tornam-se importante os meios que assegurem a manutenção da sua saúde como também da sua proteção.

$\mathrm{Na}$ atualidade, uma alternativa de baixo custo é o uso do método contraceptivo farmacológico, por meio de drogas anticonceptivas, que previnem ou retardam o estro, não permitindo uma fertilidade futura. Porém, apesar de o uso do anticoncepcional ser um método barato e de fácil acesso, uma vez que é comercializado em casas de rações e lojas do gênero, e serem vendidos sem 
prescrição de um Médico Veterinário, podem ocasionar várias patologias reprodutivas (GABALDI, 1998).

Neste contexto, o objetivo deste trabalho foi realizar um levantamento da prevalência de patologias reprodutivas em cadelas submetidas à esterilização cirúrgica e sua correlação com o uso de contraceptivos hormonais.

\section{Fundamentação Teórica}

\section{MATERIAIS E MÉTODOS}

Este trabalho consistiu num estudo descritivo, de corte transversal para a qual foi utilizada a abordagem quantitativa com o objetivo de informar sobre a distribuição de um evento, na população, em termos quantitativos. Foi analisada a relação exposição-doença, em uma dada população, em um particular momento fornecendo um retrato de como as variáveis estão relacionadas.

O estudo foi realizado com registros retrospectivos da base de dados de animais do Centro de Controle de Zoonoses (CCZ) de Resende/RJ, de modo a identificar as análises clínicas no período compreendido entre 1 de agosto a 30 de novembro de 2019. Durante esse período foram realizados atendimentos 3 vezes por semana.

Neste trabalho, apenas foram incluídos relatórios com lesões neoplásicas da glândula mamária na espécie canina.

Através da consulta dos casos clínicos no sistema informático do CCZ, analisaram-se individualmente todos os casos de maneira a selecionar a informação mais relevante. Foi possível consultar o sexo, idade, raça, porte, situação reprodutiva (esterilizada ou não), histórico clínico, administração de anovulatórios e técnica cirúrgica. No caso de dados clínicos como a administração de anovulatórios, a aplicação de terapias adjuvantes, presença de 
doenças concomitantes e a presença de recidivas e metástases não estarem nos registros clínicos, considerou-se que não se verificava a sua presença ou administração.

Após a consulta dos registros clínicos, verificou-se que apenas 19 das 100 cadelas presentes no estudo tinham informações referentes à sua identificação, nomeadamente raça e idade. Os proprietários foram questionados sobre o estado reprodutivo no momento da cirurgia, a administração de anovulatórios, tratamentos adjuvantes e recidivas. A informação relativa às metástases e às recidivas questionadas aos proprietários não foram consideradas neste estudo.

O programa informático utilizado para a elaboração da base de dados e para a análise estatística descritiva de caracterização das amostras foi o Microsoft Office Excel (Microsoft, EUA). Realizou-se análise estatística descritiva para caracterização das amostras.

\section{RESULTADOS E DISCUSSÃO}

Os resultados de prevalência de neoplasias mamárias, de acordo com raça, idade, uso de contraceptivos, localização e esterilização, em cadelas atendidas no Centro de Controle de Zoonoses, Resende - RJ, durante o ano de 2019, estão discriminados nas tabelas 1, 2, 3, 4 e 5 .

No presente estudo, foi verificada a presença de neoplasias mamárias apenas em fêmeas caninas, não sendo observados machos com a patologia. Resultados diferentes foram obtidos por Oliveira Filho et al. (2010) que encontraram 0,3\% de machos com neoplasias mamárias em 1.304 animais avaliados.

Em outro estudo retrospectivo Mitchell et al. (1974), relatou que dos 357 cães acometidos por neoplasias mamárias, apenas 1,7\% era macho. Segundo Rutteman et al. (2001), o risco de desenvolvimento desses tumores em machos é 
cerca de 1\% comparado com o verificado nas fêmeas. Provavelmente essa diferença entre os percentuais encontrados se deva ao número de animais estudados, pois certamente com o aumento do números de animais e período avaliados iriam aparecer animais do sexo masculino apresentando neoplasias mamárias. Dentre os animais avaliados, todas as 19 cadelas foram submetidas à ovaviosalpingohisterectomia (OSH) com presença de tumor mamário.

Relativamente às raças presentes no estudo (Tabela 1) foi possível observar que as mais frequentes por ordem crescente foram a raça Boder Colie, o Husky Siberiano, o Poodle e os sem raça definida (SRD).

$\mathrm{Na}$ presente amostra, os animais de raça pura (Tabela 1) foram menos comuns que os animais SRD, contradizendo Merlo (2008) e Vascellari et al. (2016), que nos seus estudos observaram uma maior percentagem de animais de raça pura comparativamente aos de raça indeterminada.

A discussão da prevalência das raças mais acometidas neste estudo fica limitada, pois não se conhece a população canina total da região. Entretanto, algumas observações são relevantes. Em um estudo realizado por Sorenmo (2003), este apontou dentre as raças caninas Poodle, Cocker Spaniel, Teckel e Pastor Alemão, como tendo maior risco de desenvolvimento de tumores mamários. Para Egenvall et al. (2005) e Riviera et al. (2009), a incidência também depende do tempo médio de vida de cada raça. No geral, as raças de maior porte têm uma vida útil naturalmente mais curta e, portanto, tendem a ser mais jovens que as raças de menor porte quando são diagnosticadas.

Ao analisar a idade das cadelas, acometidas por neoplasias mamárias neste estudo (Tabela 2), foi possível concluir que a faixa etária variou de 4 a 12 anos, com média de 7,6 anos. Sendo valor este inferior ao relatado por Oliveira filho et al. (2010), que obteve uma média de 9,2 anos em 1.647 animais avaliados. 
Segundo Rutteman et al. (2001) a média da faixa etária descrita para formação dos tumores mamários está entre 10 e 11 anos. Ainda assim, médias mais baixas, entre 7,3 e 9,5 anos, já foram relatadas (YAMAGAMI et al., 1996; EGENVALL et al., 2005 e SORENMO et al., 2009), corroborando com o encontrado neste estudo, onde é possível observar maior dominância de patologias entre os animais com 5 e 10 anos de idade $(68,4 \%)$.

Quanto ao uso de contraceptivos farmacológicos (Tabela 3) foram registrados 78,9\% (15/19) de fêmeas, que na anamnese havia a informação do uso de anticoncepcional, pelo menos uma vez, e que foram submetidos a OSH. Porém, não foi informado qual contraceptivo hormonal farmacológico administrado nas cadelas deste levantamento, o que limita muito a discussão das informações aqui obtidas. É sabido que o tratamento com contraceptivos farmacológicos a base de progesterona ou progestinas sintéticas estão relacionados ao aumento no número de casos de hiperplasias e neoplasias mamárias benignas.

Honório et al. (2017) relataram ter encontrado um percentual inferior $16,2 \%(40 / 247)$ de animais que foram submetidos ao uso de anticoncepcionais em estudo retrospectivo entre os anos de 2012 e 2014. Segundo Sorenmo (2003) e Lana et al. (2007), a porcentagem de casos da doença aumenta quando o animal é exposto ao uso de método contraceptivo hormonal.

Uma das principais maneiras de diminuir a superpopulação de cães tem sido a esterilização cirúrgica. Ainda assim, muitos proprietários possuem receio pela falta de informação e por considerarem o procedimento agonizante e invasivo (HONÓRIO, et al., 2017).

De acordo com Coronato (2016), cerca de $42 \%$ dos tutores de cães no Brasil preferem não castrar seus animais. Diante disso, muitos tutores acabam priorizando outros métodos para evitar a reprodução de seus animais. Um deles 
é o uso de anticoncepcionais, por serem baratos, de fácil disponibilidade, e por parecerem um método mais seguro num primeiro momento.

Os anticoncepcionais ficaram famosos no final da década de 80 e início da década de 90. Esses fármacos compõem-se de uma grande quantidade de hormônios que proporcionam a inibição do ciclo estral e ovariano (HONÓRIO et al., 2017). Porém, o uso frequente e/ou inadequado dos anticoncepcionais, pode resultar em inúmeras consequências negativas para o animal (FONSECA et al., 2014). Dentre esses efeitos adversos, tem-se a piometra, neoplasias mamárias e mortalidade fetal quando usado na gestação (GABALDI, 1998; SIMPSON et al., 1998 e PAPICH, 2012).

Em estudo posterior, Dias et al. (2013) reportaram que somente uma administração de contraceptivos farmacológicos já favorece o desenvolvimento de neoplasias mamárias.

Segundo Fonseca et al. (2014) existem dois análogos sintéticos à P4 mais utilizados, sendo eles o Acetato de Medroxiprogesterona (MD) e o Acetato de Megestrol (MG). Dias et al. (2013) relataram que esses hormônios progestágenos exógenos possuem longa ação e podem ser administradas pela via parenteral e oral respectivamente. Esses fármacos permitem a inibição dos hormônios gonadotróficos, prevenindo o crescimento folicular ovariano, a secreção de estrógeno, a ovulação e o comportamento sexual, impedindo de forma reversível o ciclo estral das cadelas, interrompendo o estro e a gestação, mas a efetividade não é garantida (OLIVEIRA et al., 2003).

A utilização desses fármacos é contraindicada nas fases de proestro, estro e diestro, da mesma maneira em fêmeas pré-púberes, diabéticas e em casos de patologias reprodutivas e/ou das glândulas mamárias (FONSECA et al., 2014). Segundo Silva (2016) essa droga deve ser aplicada unicamente em fêmeas adultas e que estejam em anestro. Dessa forma, o Médico Veterinário possui grande 
importância para identificação do período exato para aplicação da droga. Nesse contexto, para o diagnóstico final, pode ser realizado o exame de citologia vaginal (FONSECA et al., 2014).

Ramos e Leite (2016) relataram que o uso de contraceptivos hormonais farmacológicos aumenta a concentração de receptores para a progesterona no útero. Sabe-se que o hormônio feminino, progesterona, é responsável por manter o crescimento endometrial e a secreção glandular e, ao mesmo tempo, suprimir a atividade do miométrio, levando ao acúmulo de fluídos, e consequentemente formando um excelente ambiente para o crescimento bacteriano (ETTINGER e FELDMAN, 2001 e SANCHES, 2015).

Logo, o uso inadequado e/ou prolongado dos contraceptivos farmacológicos pode resultar em polidipsia, polifagia, letargia, risco do desenvolvimento de diabetes melito, piometra e hiperplasia das glândulas mamárias (FONSECA et al., 2014), além de acromegalia, supressão da glândula adrenal (MONTEIRO et al., 2009), alterações hepáticas, fechamento ósseo prematuro, vômito, sialorréia (DIAS et al., 2013) e obesidade (OLIVEIRA et al., 2003).

Bueno e Rédua (2019), em estudo para analisar o conhecimento dos tutores de cadelas a respeito dos métodos contraceptivos e dos riscos ocasionados pelo uso de anticoncepcional (através de questionário), reportaram que 49\% dos participantes não conheciam os perigos dos métodos contraceptivos farmacológicos e que apenas $6,7 \%$ já tinham feito o uso de anticoncepcional em seus animais.

Sabendo-se dos vários problemas que podem ser ocasionados pelo uso inadequado dos anticoncepcionais, alguns dos motivos que levam os proprietários de cães a utilizá-los são principalmente o baixo custo e a fácil acessibilidade comercial (MONTANHA et al., 2012), somado a outro fator 
complicador, a aplicação em estabelecimentos não adequados, por profissionais não habilitados, que não respeitam a dose, o período de anestro, gestação e o peso do animal, favorecendo assim os inúmeros efeitos adversos (NEVES et al., 2003).

Em relação às glândulas mamárias mais atingidas pelas neoplasias foi observado maior número de animais com as glândulas mamárias abdominais afetadas, seguido pelas glândulas inguinais, como pode ser observado na Tabela 4.

De acordo com Morris e Dobson (2007) e Queiroga e Lopes (2002), na maioria dos casos, os tumores são localizados nas mamas inguinais, devido à maior quantidade de parênquima nessas mamas. Entretanto, a explicação mais admissível é de que há maior abundância de receptores hormonais nessas mamas, favorecendo a ocorrência de neoplasias (DONNAY et al., 1995).

No tocante a prevalência de neoplasias mamárias nas cadelas, em relação ao lado afetado (direito, esquerdo ou ambos) foram encontrados os seguintes valores; $15,8 \%(3), 42,1 \%(8)$ e $42,1 \%(8)$, respectivamente.

Na tabela 5 é possível observar os percentuais de animais acometidos por neoplasias mamárias em relação à castração, na qual observa-se que animais não submetidos a Ovariohisterectomia $(\mathrm{OH})$ apresentam maior percentual de neoplasias $(84,2 \%)$ comparado aos animais que não foram submetidos ao processo de $\mathrm{OH}$.

Brennan (1975) defendia a teoria de que a supressão hormonal teria valor terapêutico na remissão de tumores mamários que ainda estariam na fase de dependência hormonal. Entretanto, o que se observa na prática clínica e cirúrgica é que somente a $\mathrm{OH}$ não promove a remissão do tumor, além da mesma não atuar como fator protetor de recidivas quando realizada no momento da exérese cirúrgica da neoplasia (MORRIS et al., 1998). 
Allen e Mahaffey (1989) também relataram a ausência de efeitos da OSH sobre o aparecimento de metástases, novos tumores e, ainda, sobre o prolongamento de vida dos animais portadores de neoplasias mamárias, quando realizada no momento da mastectomia. Contrariando Misdorp (1988), que relatou o possível efeito protetor da $\mathrm{OH}$ contra recidivas, em algumas cadelas portadoras de neoplasias mamárias, porém, não conseguiu suporte estatístico.

Yamagami et al. (1996) pesquisaram o papel da $\mathrm{OH}$, quando realizada no momento da mastectomia, em cadelas portadoras de neoplasias mamárias, e os resultados obtidos demonstraram que essa prática não tem efeito sobre o prognóstico e sobrevida dos animais com tumores.

Posteriormente, Fonseca e Daleck (2000) verificaram que o índice do desenvolvimento de neoplasias mamárias varia em cadelas castradas e não castradas, dependendo também da fase em que a esterilização cirúrgica é efetuada. Já Rutteman et al. (2001) reportaram que uma redução dos casos de neoplasias mamárias é observada se a $\mathrm{OH}$ for realizada precocemente, antes do primeiro ciclo estral, apresentando um risco de $0,5 \%$, após o primeiro estro $8 \%$ e, após o segundo estro, 26\%. Entretanto, Fonseca e Daleck (2000) reportaram que a perda do efeito protetor ocorre se a $\mathrm{OH}$ for realizada após o terceiro ciclo estral ou após dois anos e meio de idade.

Em relação as alterações associadas às neoplasias mamárias, dos 19 animais atendidos no presente levantamento, apenas 7 apresentaram outros tipos de tumores, sendo a piometra o de maior ocorrência 21,1\%(4/7), corroborando com inúmeros trabalhos (NISKANEN e THRUSFIELD, 1998; KUTZLER e WOOD, 2006; OLIVEIRA e MARQUES JÚNIOR, 2006; CHEN et al., 2007; OLIVEIRA et al., 2008; MONTEIRO et al., 2009; EVANGELISTA et al., 2011; SILVA et al., 2012 e SBIACHESKI e DA CRUZ, 2016), que mencionaram a íntima relação entre a administração de anticoncepcionais com essa afecção, 
provavelmente devido ao fato desses fármacos potencializarem os hormônios sexuais endógenos já atuantes no sistema reprodutivo. O que segundo Kutzler e Wood (2006) e Oliveira e Marques Jr. (2006), proporciona o relaxamento da cérvix, permitindo a entrada de bactérias da microbiota vaginal para o útero.

Esse baixo percentual de patologias encontradas se deve em parte ao curto intervalo de avaliação (agosto a novembro de 2019) e principalmente pelo fato dos demais animais que não foram submetidos à $O S H$, não terem tido uma avaliação clínica e histopatológica para identificar possíveis alterações.

Neste estudo, a prevalência de neoplasias mamárias encontradas foi de 19\% em um total de 100 fêmeas avaliadas. Valor este bem inferior ao encontrado por Oliveira Filho et al. (2010), que, ao avaliar 1.299 cadelas no período de 2004 a 2008, encontraram uma prevalência de tumores mamários variando entre 36,3\% e 49,2\%, demonstrando, mais uma vez, a importância dos neoplasmas mamários em fêmeas dessa espécie.

O estudo de casos encontrados no CCZ de Resende e a revisão de bibliografia permitem especular que a droga anticonceptiva utilizada desde a década de 80, ainda não proporcionou o controle populacional desejado, e predispõe os animais a enfermidades cuja terapia é cirúrgica, o que aumenta o risco de morte.

Espera-se que, com os resultados do presente estudo, sejam tomadas medidas que envolvam mais segurança na promoção, proteção, recuperação e manutenção da saúde dos animais, e que estes possam ser avaliados com maior rigor, principalmente aos animais que se opta pelo uso do método da contracepção hormonal, tendo em vista os riscos, muitas vezes irreparáveis, a que se predispõem à saúde dos mesmos.

\section{Considerações Finais}


Pode-se concluir que a utilização de fármacos contraceptivos em cadelas, para retardar ou suprimir a fase de aceitação sexual dos animais, além das alterações indesejadas causadas pelo cio dos animais, mesmo sendo usada em doses terapêuticas, o uso dessas substâncias pode provocar efeitos indesejáveis, como as patologias supracitadas diagnosticadas neste trabalho.

A grande maioria dos tutores não conhecem os perigos causados pelo uso incorreto do anticoncepcional. Salienta-se ainda que o Médico Veterinário tem papel fundamental na orientação (época adequada para uso dos anticoncepcionais) e conscientização da população, indicando a $\mathrm{OSH}$ por proporcionar uma vida mais longa e saudável para as cadelas, além de abolir o uso incorreto desse fármaco.

\section{Referências}

ALLEN, S.W.; MAHAFFEY, E.A. Canine mammary neoplasia: prognostic indicators and response to surgical therapy. Journal of the American Animal Hospital Association,v.25, p.540-546, 1989.

BITTENCOURT, C.R.; SOUZA, N.T.F.; BRAGA, K.F.; BIONDO, A.W.; RIBAS, C.R.; GUÉRIOS, S.D. Unidade Móvel de Esterilização e Educação em Saúde no ano de 2012. In: $34^{\circ}$ Congresso Brasileiro da Anclivepa, Rio Grande do Norte. CD dos Anais do CBA, 2013.

BRENNAN, M.J. Endocrinology in cancer of the breast: status and prospects. American Journal of Clinical Pathology, v.64, p.797-809, 1975. 
BUENO, L.C.V.; RÉDUA, C.R.O. Uso e consequência dos principais métodos contraceptivos em cadelas na região do Distrito Federal. Anais do 15 Simpósio de TCC e 8 Seminário de IC do Centro Universitário ICESP. n.15, p.1480-1487, 2019.

CARVALHO, T.B.; BORGES, A.P.B.; GANNS, C.M.C.; FONTES, E.P.B.; SENA, M.P.T.; LANG A. Neoplasia mamária em cadelas: expressão de proteínas de estresse (HSP 72). Veterinária e Zootecnia. v.15, p.19-22, 2008.

CHEN, R.F.F.; ADDEO, P.M.D.; SASAKI, A.Y. Piometra aberta em uma cadela de 10 meses. Revista Acadêmica, v.5, p.317-322, 2007.

CORONATO, M. 3 comportamentos péssimos que levam ao abandono de animais, medidos pelo Ibope. Revista Época, 13 junho 2016. Acessado em outubro de 2019. https://epoca.globo.com/vida/noticia/2016/06/3comportamentos-pessimos-que-levam-ao-abandono-de-animais-segundo-oibope.html

DE NARDI, A.B, RAPOSO-FERREIRA, T.M.M, ASSUNÇÃO, K.A. Neoplasias mamárias. In: Oncologia em cães e gatos. p.499-516, 2016.

DIAS, L.G.G.G.; OLIVEIRA, M.E.; FERNANDA, G.G.D.; CALAZANS, S.G.; CONFORTI, V.A. Uso de fármacos contraceptivos e seus efeitos adversos em pequenos animais. Enciclopédia Biosfera, Centro Científico Conhecer Goiânia, v.9, n.16, 2013.

DONNAY, I.; RAUIIS, J.; DEVLEESCHOUWER, N.; WOUTERS-BALLMAN, P.; LECLERCQ, G.; VERSTEGEN, J. Comparison of estrogen and progesterone 
receptor expression in normal and tumor mammary tissues from dogs. American Journal Veterinary Research, Chicago, v.56, n.9, p.1188-1194, 1995.

EGENVALL, U.; BONNETT, B.N.; ÖHAGEN, P.; OLSON, P.; HEDHAMMAR, A.; VON EULER, H. Incidence of and survival after mammary tumors in a population of over 80.000 insured female dogs in Sweden from 1995 to 2002. Preventive Veterinary Medicine, Amsterdam, v.69, 2005.

ETTINGER, S.J.; FELDMAN, E.C. Tratado de Medicina Interna veterinária Volume II: Doenças do cão e gato. $5^{\circ}$ ed. Rio de Janeiro: Guanabara Koogan, v.2, p.1084, 2001.

EVANGELISTA, L.S.M.; QUESSADA, A.M.; LOPES, R.R.F.B.; ALVES, R.P.A. GONÇALVES, L.M.F.; DRUMOND, K.O. Perfil clínico e laboratorial de gatas com piometra antes e após ovário-histerectomia. Revista Brasileira de Reprodução Animal, v.35, n.3, p.347-351, 2011.

FONSECA, C.S.; DALECK, C.R. Neoplasias mamárias em cadelas: influência hormonal e efeito da ovário-histerectomia como terapia adjuvante. Ciência Rural, Santa Maria, RS, v.30, n.4, 2000.

FONSECA, A. P.B.; MOURA, V.M.; CHAVES, R.A.A.; LEITE, E.R.; KLEIN, R.P. Progestágenos para inibição do cio em cadelas e gatas vendidos em lojas veterinárias, ANAIS - n.35 - ANCLIVEPA, 2014.

GABALDI, S.H. Hiperplasia e prolapso vaginal em cadelas. Clínica Veterinária. p.17-18, 1998.

HENRY, C.J. Tumors of the Abdominal Cavity: Mammary Tumors. In: Cancer Management in Small Animal Pratice. Maryland: Elsevier; p.275-282, 2010. 
HONÓRIO, T.G.A.F.; FONSECA, A.P.B.; ARAÚJO, E.K.D.; MOURA, V.M.; CHAVES, R.A.A.; RODRIGUES, M.C.; KLEIN, R.P. Implicações patológicas após o uso de anticoncepcional, em cadelas situadas em Teresina-PI. PUBVET, v.11, n.2, 2017.

IBGE - Instituto Brasileiro de Geografia e Estatística. Brasileiros têm 52 milhões de cães e 22 milhões de gatos. Natureza. Acessado em 2016.

http://g1.globo.com/natureza/noticia/2016/06/brasileiros-tem-52-milhoes-decaes-e-22-milhoes-de-gatos-aponta-ibge.html

KUTZLER, M.; WOOD, A. Non-surgical methods of contraception and sterilization. Theriogenology, v.66, p.514-525, 2006.

LANA, S.E.; RUTTEMAN, G.R.; WITHROW, S.J. Tumors of the mammary gland. Small animal clinical oncology, v.4, p.619-636, 2007.

MERLO, D.F. Cancer Incidence in Pet Dogs: Findings of the Animal Tumor Registry of Genoa, Italy. Journal of Veterinary Internal Medicine. v.22, n.4, p.976-984, 2008.

MISDORP, W. Canine mammary tumours: protective effect of late ovariectomy and stimulating effect of progestins. Veterinary Quarterly, v.10, n.l, p.26-33, 1988.

MITCHELL, L.; IGLESIA, F.A.; WENKOFF, M.S.; VAN DREUMEL, A.A.; LUMB, G. Mammary tumors in dogs: Survey of clinical and pathological characteristics. Canadian Veterinary Journal. v.15, n.5, p.131-138, 1974. 
MONTANHA, F.P.; CORRÊA, C.S.S.; PARRA, T.C. Maceração fetal em gata em decorrência do uso de contraceptivos - relato de caso. Revista Científica

Eletrônica de Medicina Veterinária, v.10, n.9, p.1- 6, 2012.

MONTEIRO, C.M.R.; PERRI, S.H.V.; CARVALHO, R.G.; KOIVISTO, M.B.

Histologia e morfometria em cornos uterinos de cadelas nulíparas, multíparas e tratadas com contraceptivos. Pesquisa Veterinária Brasileira, v.29, n.10, 2009.

MORRIS, J.; DOBSON, J. Glândula Mamária. In Oncologia em Pequenos Animais. São Paulo: Roca, p.185-192, 2007.

MORRIS, J.S.; DOBSON, J.M.; BOSTOCK, D.E.; O'FARRELL, E. Effect of ovariohysterectomy in bitches with mammary neoplasms. The Veterinary Record, v.142, p.656-658, 1998.

NEVES, M.M.; MARQUES JÚNIOR, A.P.; OLIVEIRA, E.C.S. Endocrinologia reprodutiva e controle da fertilidade da cadela - revisão. Archives of Veterinary Science, v.8, n.1, p.1-12, 2003.

NISKANEN, M.; THRUSFIELD, M.V. Associations between age, parity, hormonal therapy and breed, and pyometra in Finnish dogs. Veterinary Record, v.143, p.493-498, 1998.

OLIVEIRA, E.C.S.; MARQUES-JR, A.P. Endocrinologia reprodutiva e controle da fertilidade da cadela. Revista Brasileira de Reprodução Animal, v.30, p.11$18,2006$. 
OLIVEIRA, E.C.S.; MARQUES JÚNIOR, A.P.; NEVES, M.M. Endocrinologia reprodutiva e controle da fertilidade da cadela, Archives of Veterinary Science, v.8, n.1, 2003.

OLIVEIRA FILHO, J.C.; KOMMERS, G.D.; MASUDA, E.K.; MARQUES, B.M.F.P.P.; FIGHERA, R.A.; IRIGOYEN, L.F.; BARROS C.S.L. Estudo retrospectivo de 1.647 tumores mamários em cães. Pesquisa Veterinária Brasileira. v.30, n.2, p.177-185, 2010.

OLIVEIRA, N.G.; KOSHYAMA, M.H.I.; CRISTINA, S.; SCANDURA, M.A.B.; LEME, F.F.; LÚCIA, M.; MARCUCCI, M.L.G.L.; OLIVEIRA, P.C. Uso de aglepristone e cloprostenol no tratamento de piometra em cadela - relato de caso. Unifeob. São João da Boa Vista, 2008.

PAPICH, M.G. Manual Saunders de Terapia Veterinária. Elsevier Health Sciences Brazil, 2012.

QUEIROGA, F.E.; LOPES, C. Tumores Mamários Caninos, Pesquisa de Novos Fatores de Prognóstico. Revista Portuguesa de Ciências Veterinárias, v.97, p.119-127, 2002.

RAMOS, L.T.; MELO, LEITE, A.K.R. Perfil da população canina diagnosticada com piometra atendida na unidade hospitalar veterinária da Universidade Estadual do Ceará no período de janeiro a agosto de 2012. Revista Científica de Medicina Veterinária - Ano XIV, n.27 - Julho - Periódico Semestral, 2016.

RIVERA, P.; MELIN, M.; BIAGI, T.; FALL, T.; HAGGSTROM, J.; LINDBLADTOH, K.; VON EULER, H. Mammary tumor development in dogs is associated 
with BRCA1 and BRCA2. Molecular Biology, Pathobiology, and Genetics. Novembro 15, v.22, n.69, p.8770-8774, 2009.

RUTTEMAN, G.R.; WITHROW, S.J.; MACEWEN, E.G. Tumors of the mammary gland. In: WITHROW, S.J \& MACEWEN, E.G. (Eds.), Small animal clinical oncology ( $3^{\text {rd }}$ ed.). Saunders Elsevier, Philadelphia, p.455-477, 2001.

SANCHES, F.S.C.; PEREIRA G.Q.; FILHO, M.D.M.; SILVA, L.C.; OKANO, W.; KEMPER, D.A.G.; KEMPER, B. Avaliação bacteriológica uterina de cadelas com piometra. Revista de Higiene e Sanidade Animal Braziliana, Fortaleza, v.9, n.1, 2015.

SBIACHESKI, D.T.; DA CRUZ, F.S.F. Uso de progestágenos e seus efeitos adversos em pequenos. XXIV Seminário de Iniciação Científica, Injuí, 2016. Acessado em: 12 de dezembro de 2019.

file://C:/Users/user/Downloads/6360-Texto\%20do\%20artigo-27778-11020160912.pdf

SILVA, L.D.M. Controle do ciclo estral em cadelas. Revista Brasileira de Reprodução Animal, Belo Horizonte, v.40, n.4, 2016.

SILVA, A.C.; SILVA, C.E.S.; PELUSO, E.M.; TUDURY, E.A. Esterilização em gatas mediante salpingectomia parcial (incluindo prenhes) versus ovariosalpingohisterectomia. Ciência Rural, v.42, n.3, p.507-513, 2012.

SIMPSON, G.; ENGLAND, G.C.W.; HARVEY, M. BSAVA manual of small animal reproduction and neonatology. British Small Animal Veterinary Association, London, 1998. 
SORENMO, K.U. Canine mammary gland tumors. Veterinary Clinics North America: Small Animal Practice. v.33, p.573-596, 2003.

SORENMO, K.U.; KRISTIANSEN, V.M.; COFONE, M.A.; SHOFER, F.S.;

BREEN, A.M.; LANGELAND, M.; MONGIL, C.M.; GRONDAHL, A.M.; TEIGE, J.; GOLDSCHMIDT, M.H . Canine mammary gland tumours; a histological continuum from benign to malignant; clinical and histopathological evidence. Veterinary and Comparative Oncology, Oxford, v.7, n.3, p.162-172, 2009.

VASCELLARI, M.; CAPELLO, K.; CARMINATO, A.; ZANARDELLO, C.; BAIONI, E.; MUTINELLI, F. Incidence of mammary tumors in the canine population living in the Veneto region (Northeastern Italy): Risk factors and similarities to human breast cancer. Medicina Veterinária Preventiva. v.126, p.183-189, 2016.

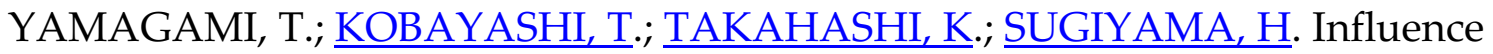
of ovariectomy at the time of rnastectomv on the prognosis for canine malignant mammary turnours. Journal of Small Animal Practice, Oxford, v.37, p.462-464, 1996.

\section{Apêndices}

Tabela 1 - Prevalência de neoplasias mamárias em cadelas de acordo com a raça, atendidas no Centro de Controle de Zoonoses, Resende - RJ, durante o ano de 2019.

\begin{tabular}{lcc}
\hline \multicolumn{1}{c}{ Raça } & N & \% \\
\hline Boder Colie & 1 & 5,3 \\
Husky Siberiano & 1 & 5,3 \\
Poodle & 2 & 10,5
\end{tabular}




\begin{tabular}{lll} 
SRD & 15 & 78,9 \\
\hline Total & $\mathbf{1 9}$ & $\mathbf{1 0 0}$ \\
\hline
\end{tabular}

$\mathrm{N}=$ número de cadelas, $\%$ = porcentagem.

Tabela 2 - Prevalência de neoplasias mamárias em cadelas de acordo com a idade, atendidas no Centro de Controle de Zoonoses, Resende - RJ, durante o ano de 2019.

\begin{tabular}{lcc}
\hline \multicolumn{1}{c}{ Idade (anos) } & $\mathbf{N}$ & \% \\
\hline $0-5$ & 4 & 21,1 \\
$5-10$ & 13 & 68,4 \\
$>10$ & 2 & 10,5 \\
\hline Total & $\mathbf{1 9}$ & $\mathbf{1 0 0}$ \\
\hline
\end{tabular}

$\mathrm{N}=$ número de cadelas, $\%=$ porcentagem.

Tabela 3 - Prevalência de neoplasias mamárias em cadelas de acordo com o uso de contraceptivos, atendidas no Centro de Controle de Zoonoses, Resende - RJ, durante o ano de 2019.

\begin{tabular}{lcc}
\hline \multicolumn{1}{c}{ Uso Contraceptivos } & $\mathbf{N}$ & $\mathbf{\%}$ \\
\hline Não & 4 & 21,1 \\
Sim - 1 vez & 3 & 15,8 \\
Sim - mais 1 vez & 12 & 63,1 \\
\hline & Total & $\mathbf{1 0 0}$
\end{tabular}

$\mathrm{N}=$ número de cadelas,$\%$ = porcentagem. 
Tabela 4 - Prevalência de neoplasias mamárias em cadelas de acordo com a localização, atendidas no Centro de Controle de Zoonoses, Resende - RJ, durante o ano de 2019.

\begin{tabular}{|c|c|c|}
\hline Localização & $\mathbf{n}$ & $\%$ \\
\hline Gls. mamárias torácicas & 7 & 21,2 \\
\hline Gls. mamárias abdominais & 15 & 45,5 \\
\hline Gls. mamárias inguinal & 11 & 33,3 \\
\hline Total & 33 & 100 \\
\hline \multicolumn{3}{|c|}{$\begin{array}{l}\text { Tabela } 5 \text { - Prevalência de neoplasias mamárias em cadelas de acordo } \\
\text { com a esterilização, atendidas no Centro de Controle de Zoonoses, } \\
\text { Resende - RJ, durante o ano de } 2019 \text {. }\end{array}$} \\
\hline Histórico de castração & $\mathbf{n}$ & $\%$ \\
\hline Sim & 3 & 15,8 \\
\hline Não & 16 & 84,2 \\
\hline Total & 19 & 100 \\
\hline
\end{tabular}

$\mathrm{N}$ = número de cadelas, $\%$ = porcentagem. 